\title{
Incidence and diagnosis of unilateral arterial cerebral infarction in newborn infants *
}

\author{
Sven Schulzke1,**, Peter Weber², Juerg \\ Luetschg $^{2}$ and Hubert Fahnenstich ${ }^{1}$ \\ ${ }^{1}$ Department of Neonatology, University Children's \\ Hospital, Basel, Switzerland \\ 2 Department of Neuropediatrics, University Children's \\ Hospital, Basel, Switzerland
}

\begin{abstract}
Aims: Magnetic resonance imaging (MRI) is accepted as the gold standard for the diagnosis of arterial cerebral infarction $(\mathrm{ACl})$, but few studies have reported the incidence of neonatal $\mathrm{ACl}$ based on MRI findings. We provide new population-based epidemiologic and diagnostic data on all infants diagnosed between 1997 and 2002 in our center with an MRI-confirmed diagnosis of unilateral neonatal $\mathrm{ACl}$.
\end{abstract}

Results: Nine patients were identified, giving an incidence of 1:2300 unilateral ACls in our inborn population. In all patients the middle cerebral artery was affected. Seven patients showed epileptic seizures, usually starting within the first 3 days of life. EEG was pathologic in all patients. Only three infarctions were diagnosed by ultrasound. Initial MRI established diagnosis of $\mathrm{ACl}$ in eight out of nine patients and subsequent MRI described the exact location of infarctions in all patients. Six out of nine patients developed hemiparesis and five had deficits in language development. There is a substantial need for special care facilities and long-term therapeutic interventions.

Conclusions: The incidence of neonatal $\mathrm{ACl}$ is higher than previously reported. The sensitivity of early cerebral ultrasound for diagnosis of $\mathrm{ACl}$ is low. Seizures in the first 3 days of life combined with pathologic EEG findings should lead to $\mathrm{MRI}$, regardless of normal cerebral ultrasound.

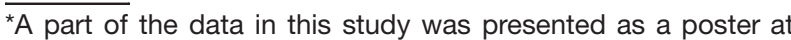
the Pediatric Academic Societies Meeting, May 2003, Seattle, WA, USA.

${ }^{* *}$ Corresponding author:

Sven Schulzke, MD

Department of Neonatology

University Children's Hospital

Roemergasse 8

$\mathrm{CH}-4005$ Basel/Switzerland

Tel.: + 41-79-619-4076,

Fax: +41-61-685-5004

E-mail: sven.schulzke@unibas.ch
}

Keywords: Arterial cerebral infarction; magnetic resonance imaging; newborn infants.

\section{Introduction}

Symptomatic unilateral arterial cerebral infarction (ACI) in newborn infants usually occurs in the territory of a major cerebral artery, most often in the middle cerebral artery (MCA) [1], with a predominance of the left side [3]. The majority of infants do not suffer from asphyxia, but present with seizures during the very first days of life [7]. Cranial magnetic resonance imaging (MRI) is accepted as the gold standard for the diagnosis of $\mathrm{ACl}$ [8], while the diagnostic role of cerebral ultrasound is controversial $[1,4,5]$. Few studies have used MRI for diagnosis during the neonatal period $[1,8]$ and few population-based epidemiologic data exist. Most authors estimate an incidence of 1:4000 ACls based on a study that used computed tomography (CT) and data from 1987-1993 $[2,10]$. With neonatal MRI routinely available, we hypothesize that detection rates of $\mathrm{ACl}$ should be higher. The objective of this study was to provide current populationbased epidemiologic data on the incidence of unilateral $\mathrm{ACl}$ in newborns and to elucidate the diagnostic value of newborn seizures, electroencephalography (EEG), cerebral ultrasound and $\mathrm{MRI}$ for the diagnosis of $\mathrm{ACl}$.

\section{Methods}

\section{Patients}

All newborns born between 1/1/1997 and 12/31/2002 and diagnosed in the University Children's Hospital, Basel with a discharge diagnosis of MRI-proven unilateral $\mathrm{ACl}$ were identified using full-text searchable electronic databases of patient records and by hand-searching discharge letters from the Department of Neonatology and the Department of Pediatric Neurology.

\section{Population}

Our perinatal center consists of two major women's hospitals of the two Swiss cantons Basel-Stadt and BaselLandschaft, with two associated tertiary-care neonatal units of the University Children's Hospital, Basel. The two 
women's hospitals cover $50 \%$ of all deliveries in the two cantons and serve as both regional hospitals and referral centers. Inborn newborns were born in the two abovementioned hospitals. In addition, there are four obstetric departments within the two provinces referring ill outborn children, and four hospitals in neighboring provinces that refer critically ill outborn children. Hospitals referring outborn children were free to choose our center for neonatal care or others from neighboring provinces. Therefore, to allow for a well-defined population, incidence was calculated for inborn children only, based on total birth rates from 1997 to 2002 in the two associated women's hospitals.

\section{Evaluation of patient data}

Information was obtained from obstetric and pediatric patient records. Patient charts, EEGs, cerebral ultrasounds, MRI images and data on neurodevelopmental follow-up were evaluated retrospectively.

\section{Diagnostic procedures}

All instrumental diagnostic procedures were performed during routine neonatal care. Initial EEGs with a minimum duration of $30 \mathrm{~min}$ and cerebral ultrasound studies were recorded in the neonatal intensive care unit (NICU) within $48 \mathrm{~h}$ after the onset of seizures. Ultrasound was carried out by consultant neonatologists and certified pediatric radiologists using Aloka SSD-1700 and Medison Digital Gaia ultrasound scanners with $5-7.5-\mathrm{MHz}$ multifrequency sector transducers. MRI was carried out on a 1.0-T Picker system during the neonatal period in all but three patients (numbers 3,4 and 7 ), who received their first $\mathrm{MRI}$ at the ages of 2, 3 and 8 months of life, respectively.

\section{Results}

\section{Identified patients}

From 11 patients with $\mathrm{MRI}-$ proven $\mathrm{ACl}$, two were excluded because of multiple bilateral infarctions following severe asphyxia. Eight out of nine infants with unilateral $\mathrm{ACl}$ were identified during the neonatal period; one boy, who was without pathological findings as a neonate, was admitted to our center at the age of 4 months because of left-sided spasticity. Infants were born between 35 and 42 weeks of gestation. There were 13,901 inborn live births during the study period, and six of the nine identified patients were inborn. This translates to an incidence of 1:2316 unilateral neonatal ACls. Characteristics and diagnostic details of all patients are shown in Table 1.

\section{Diagnostic features}

Seven out of nine patients showed neonatal seizures, and in six patients seizures started within the first 3 days of life. In four patients we observed focal clonic seizures, while three patients presented with generalized seizures consisting of apnea and generalized clonic and tonic convulsions. EEG recordings from all identified neonates were carried out within $48 \mathrm{~h}$ of the onset of seizures. All neonatal EEG recordings showed pathologic findings as follows: abnormal lateralized background (5), periodic lateralized epileptiform discharges (1), and focal hypersynchrony (7). In only three of eight patients did cerebral ultrasound show focal echogenic lesions suggesting $\mathrm{ACl}$.
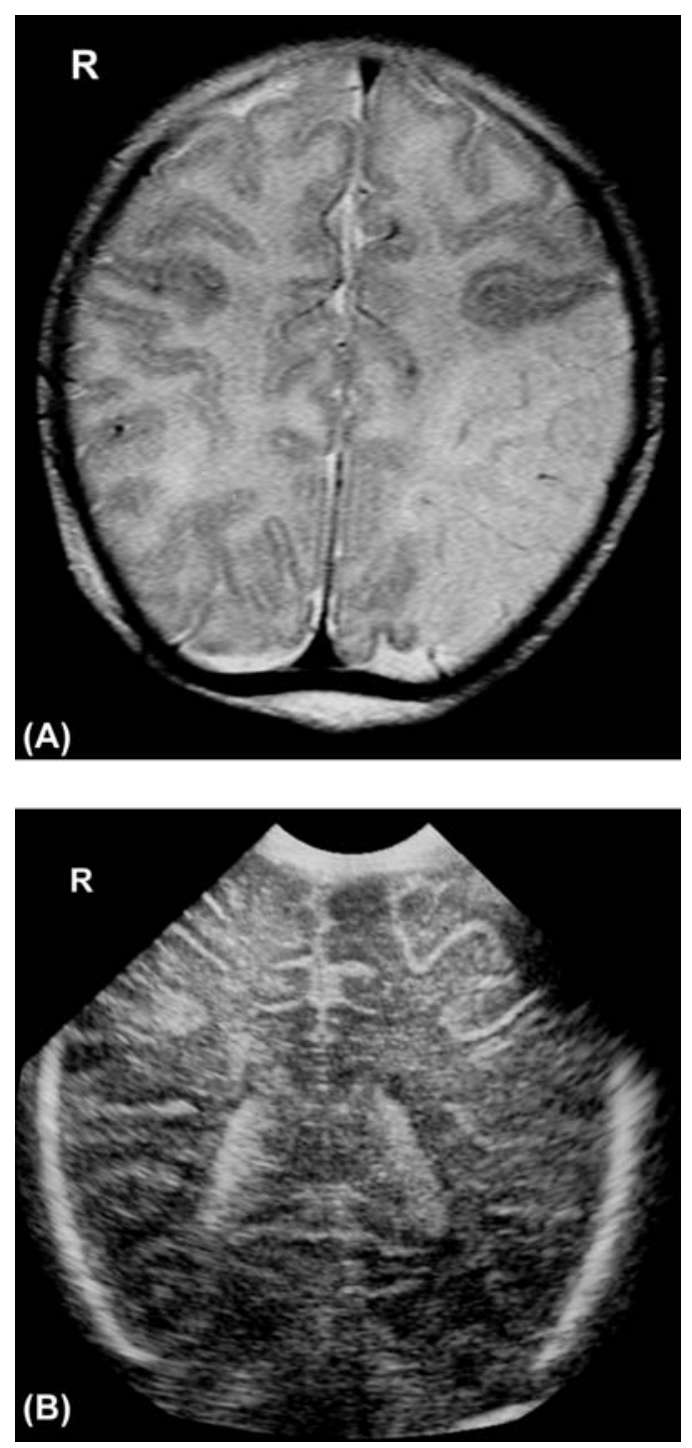

Figure 1 (A) Axial T1-weighted MRI (day 7) and (B) coronal cerebral ultrasound (day 5) of patient no. 8. MRI shows enhanced signal intensity of the left posterior hemisphere due to ischemic infarction of the left middle cerebral artery, while the cerebral ultrasound is unremarkable. 


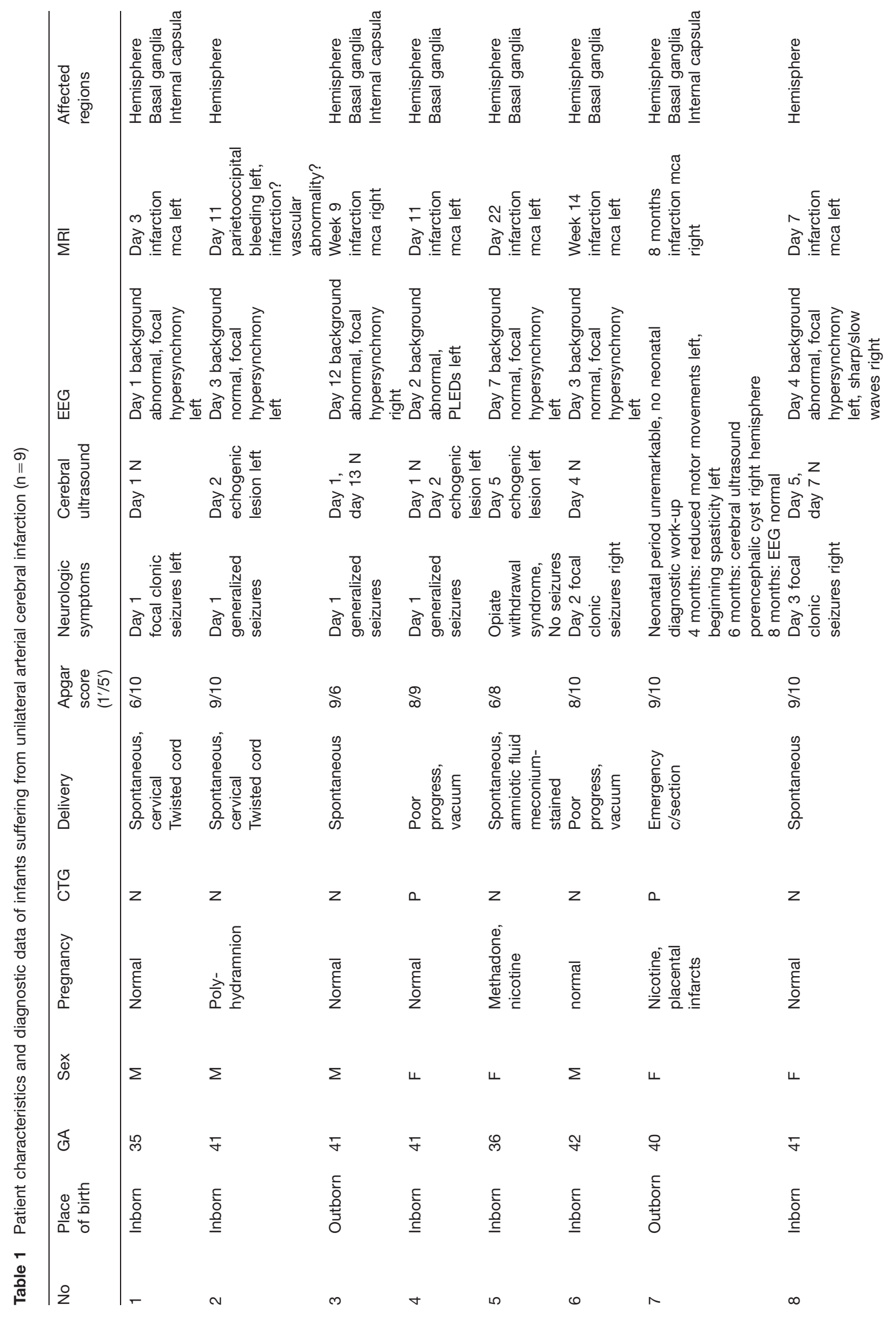




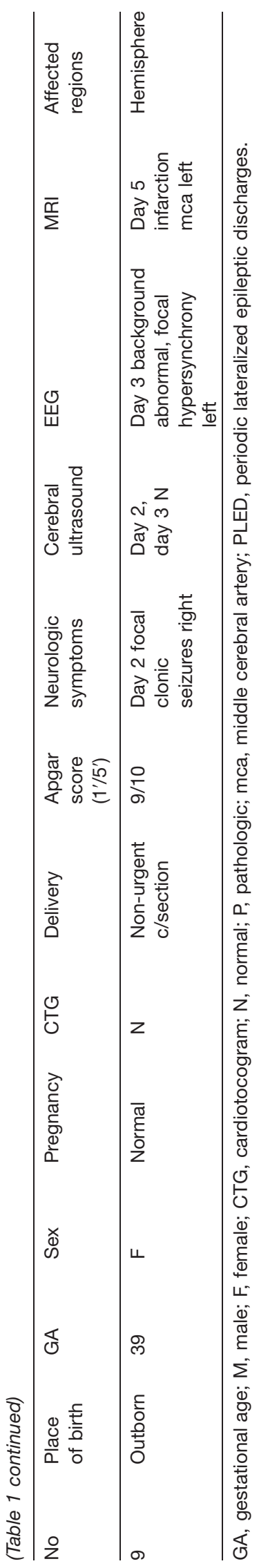

MRI confirmed the diagnosis of $\mathrm{ACl}$ in these three cases. Doppler studies were routinely carried out, but this was never helpful for the diagnosis of $\mathrm{ACl}$.

Regarding MRI, a diagnosis of $\mathrm{ACl}$ was confirmed in eight out of nine cases after the first MRI scan. In one child, an initial MRI on day 11 showed considerable leftsided bleeding, suggesting hemorrhagic infarction of the left MCA, but bleeding due to a vascular malformation could not be ruled out. After resorption of the hematoma, subsequent MRI scans established the diagnosis of ACI. All patients had unilateral infarction of the middle cerebral artery (Figure 1). Seven out of nine infarctions were leftsided and two were right-sided. For details on the affected cerebral structures, see Table 1.

\section{Neurological outcome}

Six out of nine children developed hemiparesis, while two continued to show epileptic seizures after the neonatal period. Language development was delayed in five out of nine children. There is a substantial need for special care school facilities and long-term therapeutic interventions, as detailed in Table 2.

\section{Discussion}

The incidence of ca. 1:2300 unilateral neonatal ACls in our population is higher than in another populationbased study [2] in which an incidence of 1:4000 was calculated using cranial CT for confirmation of diagnosis. This discrepancy may be due to the fact that the sensitivity of MRI for diagnosis of $\mathrm{ACl}$ is superior to that of $\mathrm{CT}$ [6].

Newborn seizures were present in seven out of nine patients, a fact that underlines the value of this clinical condition for the diagnosis of $\mathrm{ACl}$. As helpful as seizures are for initiation of the diagnostic and therapeutic process, two patients were without corresponding neurologic symptoms in the neonatal period. It remains unclear how these patients can be identified at an early date, because there are no predictive markers available. Furthermore, it is not known whether ACls diagnosed acutely and retrospectively differ in the time of occurrence or pattern of injury [10].

All patients identified during the neonatal period had pathologic EEG recordings. Five out of eight EEG readings showed abnormal lateralizing background activity, indicating poor prognosis regarding the development of hemiparesis [8]. Only one patient showed periodic lateralized epileptiform discharges (PLEDs), known to be pathognomonic for unilateral $\mathrm{ACl}$ [9]. We may have missed PLEDs in other patients, as our EEG recordings lasted only 30-60 min, and were thus of a shorter duration than those reported in recent studies [8,9], which used continuous EEG for nearly 2 days. 
Table 2 Neurological and developmental outcomea of newborn infants suffering from unilateral arterial cerebral infarction $(n=9)$.

\begin{tabular}{|c|c|c|c|c|c|c|c|}
\hline No & $\begin{array}{l}\text { Motor } \\
\text { Development }\end{array}$ & Epilepsy & $\begin{array}{l}\text { Language } \\
\text { development }\end{array}$ & $\begin{array}{l}\text { Age-appropriate } \\
\text { communication/ } \\
\text { play behavior }\end{array}$ & $\begin{array}{l}\text { School } \\
\text { type }\end{array}$ & $\begin{array}{l}\text { Current } \\
\text { therapy/ } \\
\text { support }\end{array}$ & $\begin{array}{l}\text { Follow } \\
\text { up } \\
\text { (months) }\end{array}$ \\
\hline 1 & $\begin{array}{l}\text { Hemiparesis } \\
\text { Arm > leg }\end{array}$ & + & Delayed & No & $\begin{array}{l}\text { Special } \\
\text { care }\end{array}$ & $\begin{array}{l}\text { Physio } \\
\text { Speech } \\
\text { OT }\end{array}$ & 72 \\
\hline 2 & Normal & - & Normal & Yes & Normal & - & 48 \\
\hline 3 & $\begin{array}{l}\text { Hemiparesis } \\
\text { Leg > arm }\end{array}$ & - & Delayed & Yes & Normal & $\begin{array}{l}\text { Physio } \\
\text { Speech } \\
\text { OT }\end{array}$ & 48 \\
\hline 4 & $\begin{array}{l}\text { Hemiparesis } \\
\text { Arm }>\text { leg }\end{array}$ & - & Delayed & No & $\begin{array}{l}\text { Special } \\
\text { care }\end{array}$ & $\begin{array}{l}\text { Physio } \\
\text { SE, OT }\end{array}$ & 60 \\
\hline 5 & $\begin{array}{l}\text { Hemiparesis } \\
\text { Leg }>\text { arm }\end{array}$ & - & Delayed & No & $\begin{array}{l}\text { Special } \\
\text { care }\end{array}$ & $\begin{array}{l}\text { Physio } \\
\text { SE }\end{array}$ & 48 \\
\hline 6 & Hemiparesis & + & Delayed & No & $\begin{array}{l}\text { Special } \\
\text { care }\end{array}$ & $\begin{array}{l}\text { Physio } \\
\text { OT }\end{array}$ & 42 \\
\hline 7 & Hemiparesis & - & Normal & Yes & $-\mathrm{b}$ & $\begin{array}{l}\text { Physio } \\
\text { OT }\end{array}$ & 20 \\
\hline 8 & Normal & - & Normal & Yes & $-{ }^{\mathrm{b}}$ & Physioc & 24 \\
\hline 9 & Normal & - & Normal & Yes & $-\mathrm{b}$ & $\begin{array}{l}\text { Physio } \\
\text { SE }\end{array}$ & 24 \\
\hline
\end{tabular}

OT, occupational therapy; SE, special educative therapy.

aBased on Griffith's test ( $\leq 24$ months of age) or Denver developmental scale ( $>24$ months of age).

${ }^{b}$ Children are below 3 years of age.

cProphylaxis.

We assume that the low sensitivity of cerebral ultrasound results from the timing of the initial ultrasound studies, as they were carried out in the first few days of life. There is evidence from prospective trials showing higher ultrasound sensitivity when carried out at the end of or after the first week of life $[4,8]$. Cerebral Doppler studies were not helpful for the diagnosis of $\mathrm{ACl}$ in our patients. Some small series have identified transient decreases in cerebral blood-flow velocity ipsilateral to $\mathrm{ACl}$ in a proportion of affected infants [11, 12], while others did not [13]. One reason for this discrepancy could be that some infarctions might be caused by transient vasospasm rather than embolism. In addition, seizures are known to transiently increase blood flow velocity [14]. Furthermore, the inability to show reduced cerebral blood-flow velocities in our study might be due to the timing of the Doppler studies, which were carried out up to $48 \mathrm{~h}$ following the onset of seizures. Decreased blood-flow velocity in $\mathrm{ACl}$ seems to be significant only within the first $24 \mathrm{~h}$ [11]. In general, cerebral blood-flow velocity varies substantially following neonatal seizures due to $\mathrm{ACl}$, and the usefulness of these measurements in $\mathrm{ACl}$ has not yet been established [10].

Conventional MRI proved to be very sensitive for the diagnosis of $\mathrm{ACl}$. At a later date, diffusion-weighted imaging was available in our institution (and was used additionally in patients no. 8 and no. 9) and allowed early diagnosis in the first week of life. However, as bleeding due to a vascular malformation could not be ruled out after the first MRI scan in one patient, the possible need for subsequent scans should be kept in mind. Regarding neurological outcome, we found that two-thirds of our patients suffered from hemiparesis and five out of nine children showed delayed language development, mostly because of deficits in expressive language. While the frequency of hemiparesis is consistent with the literature, there are few data on language development after neonatal $\mathrm{ACl}[10]$. The majority of our patients need special care facilities and use multiple therapeutic interventions, such as physiotherapy, occupational therapy, speech therapy and special educative support, which underlines the long-term impact of neonatal $\mathrm{ACl}$ on the lives of affected patients and families, as well as healthcare resources.

In conclusion, this retrospective case series shows that in our population the incidence of unilateral $\mathrm{ACl}$ in newborns is higher than previously reported. The true incidence may even be higher than 1:2300, as not all affected infants have seizures and neurological sequelae. Seizures in the first 3 days of life and pathologic EEG findings should lead to early MRI, regardless of normal cerebral ultrasound, as ACl may be the diagnosis.

\section{Acknowledgements}

We thank Dr. Allison Sommerville for her assistance in preparing the manuscript. 


\section{References}

[1] de Vries LS, F Groenendaal, P Eken, IC van Haastert, KJ Rademaker, LC Meiners: Infarcts in the vascular distribution of the middle cerebral artery in preterm and full-term infants. Neuropediatrics 28 (1997) 88

[2] Estan J, P Hope: Unilateral neonatal cerebral infarction in full term infants. Arch Dis Child Fetal Neonatal Ed 76 (1997) F88

[3] Filipek PA, KS Krishnamoorthy, KR Davis, K Kuehnle: Focal cerebral infarction in the newborn: a distinct entity. Pediatr Neurol 3 (1987) 141

[4] Fischer AQ, JC Anderson, R Shuman: The evolution of ischemic cerebral infarction in infancy: a sonographic evaluation. J Child Neurol 3 (1988) 105

[5] Golomb MR, PT Dick, DL MacGregor, DC Armstrong, GA DeVeber: Cranial ultrasonography has a low sensitivity for detecting arterial ischemic stroke in term infants. J Child Neurol 18 (2003) 98

[6] McArdle CB, CJ Richardson, CK Hayden, DA Nicholas, EG Amparo: Abnormalities of the neonatal brain: MR imaging. Part II. Hypoxic-ischemic brain injury. Radiology 163 (1987) 395

[7] Mercuri E, F Cowan, M Rutherford, D Acolet, J Pennock, L Dubowitz: Ischaemic and haemorrhagic brain lesions in newborns with seizures and normal Apgar scores. Arch Dis Child Fetal Neonatal Ed 73 (1995) F67
[8] Mercuri E, M Rutherford, F Cowan, J Pennock, S Counsell, M Papadimitriou, D Azzopardi, G Bydder, L Dubowitz: Early prognostic indicators of outcome in infants with neonatal cerebral infarction: a clinical, electroencephalogram, and magnetic resonance imaging study. Pediatrics 103 (1999) 39

[9] Mercuri E: Early diagnostic and prognostic indicators in full term infants with neonatal cerebral infarction: an integrated clinical, neuroradiological and EEG approach. Minerva Pediatr 53 (2001) 305

[10] Nelson KB, JK Lynch: Stroke in newborn infants. Lancet Neurol 3 (2004) 150

[11] Nishimaki S, K Seki, S Yokota: Cerebral blood flow velocity in two patients with neonatal cerebral infarction. Pediatr Neurol 24 (2001) 320

[12] Perlman JM, NK Rollins, D Evans: Neonatal stroke: clinical characteristics and cerebral blood flow velocity measurements. Pediatr Neurol 11 (1994) 281

[13] Taylor GA: Alterations in regional cerebral blood flow in neonatal stroke: preliminary findings with color Doppler sonography. Pediatr Radiol 24 (1994) 111

[14] Volpe JJ: Neurological evaluation: specialized studies in the neurological evaluation. In: Volpe JJ (ed): Neurology of the Newborn. $3^{\text {rd }}$ edition, W.B. Saunders Company, Philadelphia 1994

Received September 3, 2004. Revised November 23, 2004. Accepted December 1, 2004. 